\title{
Religião e identidade cultural negra: católicos, afrobrasileiros e neopentecostais
}

\author{
Vagner Gonçalves da Silva
}

Este artigo é dedicado à memória de Rita Amaral

\section{Introdução}

Estamos realizando há alguns anos uma pesquisa cujo objetivo é analisar os papeis que as religióes afrobrasileiras vêm desempenhando no processo de construção das identidades culturais de origem negra no Brasil contemporâneo ${ }^{1}$. Considerando, entretanto, que nas últimas décadas muitas denominações religiosas, além das afrobrasileiras, têm se mobilizado em torno dos símbolos da herança negra no Brasil, gerando disputas e controvérsias, este artigo pretende indicar de forma abreviada algumas possíveis linhas interpretativas deste processo $^{2}$.

Para que possamos entender alguns aspectos deste processo começarei estabelecendo algumas definições básicas destas denominações, ou melhor, das articulações que estas mantêm entre si por aproximação ou distanciamento.

Numa definição curta, apenas para esta exposição, as religiōes afrobrasileiras são basicamente religióes do transe, do sacrifício animal e do contato direto com os deuses como meio de comungar valores e estabelecer sociabilidades em comunidades relativamente pequenas. Em termos dos deuses cultuados e considerando os dois modelos mais conhecidos destas religiôes, o candomblé e a umbanda, podemos dizer que no candomblé jeje-nagô cultuam-se basicamente entidades designadas pelos termos orixá e vodum, nomes genéricos dos deuses originariamente provenientes da África
Ocidental. No candomblé angola cultuam-se os inquices, deuses originários da África Central, e caboclos, entidades que representam os espíritos da população indígena brasileira. A umbanda (religião que associou deuses africanos, santos católicos e espiritismo kardecista e esta difundida nacionalmente entre as camadas pobres e médias da população brasileira) engloba as entidades do candomblé e redefine a cosmologia num esquema evolucionário, como uma escada, com os santos e orixás ocupando os degraus mais altos. Estes são, por isso, tidos como espíritos de luz. Os caboclos e os pretos-velhos (espíritos dos africanos escravizados) são considerados espíritos intermediários. Exus e pombagiras são tidos como o lado esquerdo ou "espíritos das trevas" e estão situados no degrau mais baixo desta escala, pois estão associados ao demônio pela influência do catolicismo.

Já o catolicismo cultua basicamente a santíssima trindade (formada pelas figuras do deus-pai, deus-filho e espírito santo) e muitos intermediários como Maria (mãe do deus-filho), santos e anjos. O neopentecostalismo (religião cristã que cresceu vertiginosamente no Brasil das últimas três décadas entre as camadas pobres) se coloca entre estes sistemas e os articula como se fosse uma espécie de porta que permite ou não a passagem de um sistema para outro. Certamente que o principal objetivo do neo-pentecostalismo é eliminar todos os intermediários dos outros sistemas pela promoção da guerra contra o mal entendida como a guerra de Jesus contra Exu que é visto como se fosse a manifestação do demônio ${ }^{3}$. Brevemente 
296 | Vagner Gonçalves da Silva

\begin{tabular}{|c|c|c|c|c|c|c|}
\hline \multirow{2}{*}{$\begin{array}{l}\text { Candomblé Jeje-nagô } \\
\text { Orixá/Vodum } \\
\text { Erê }\end{array}$} & \multicolumn{2}{|c|}{$\begin{array}{l}\text { Candomblé } \\
\text { Angola }\end{array}$} & & \multicolumn{2}{|l|}{ Neopentecostalismo } & \\
\hline & $\begin{array}{l}\text { Inquice } \\
\text { Erê }\end{array}$ & Caboclo & Preto-Velho & $\begin{array}{l}\text { Exu } \\
\text { Pombagira } \\
\text { Encosto } \\
\text { Demônio }\end{array}$ & $\begin{array}{l}\text { Deus-Pai } \\
\text { Deus-Filho (Jesus) } \\
\text { Espírito Santo }\end{array}$ & $\begin{array}{l}\text { Mãe de Deus (Maria) } \\
\text { Santos }\end{array}$ \\
\hline \multirow[t]{2}{*}{ (direita) "mais luz" } & \multirow{2}{*}{\multicolumn{2}{|c|}{ Umbanda }} & \multicolumn{2}{|r|}{ "menos luz" (esquerda) } & \multicolumn{2}{|l|}{ Catolicismo } \\
\hline & & & & Quimbanda & & \\
\hline
\end{tabular}

podemos dizer que o candomblé pensa a si próprio como uma religião de origem africana na qual os orixás ocupam uma posição central e a umbanda como uma religião afrobrasileira na qual caboclos e pretos-velhos são as principais entidades. Em termos gráficos, poderíamos descrever o continuum conforme acima.

O diálogo entre o terreiro e os espaços públicos de culto na cidade historicamente garantiram a reprodução do sistema religioso para além dos muros do terreiro. Exemplificarei com um conjunto de relaçóes nesse nível. As praias do litoral brasileiro são espaços de culto fora dos terreiros. Nelas, Iemanjá, orixá feminino associado ao mar, é homenageada. Estas homenagens são feitas geralmente nos dias 2 de fevereiro e 8 de dezembro pela relação que tem com Nossa Senhora dos Navegantes e Nossa Senhora da Conceição, respectivamente. Nestas datas, são ofertados presentes a Iemanjá em grandes festivais. Mas, especialmente na noite de ano novo, milhares de pessoas, adeptas ou não das religiōes afrobrasileiras, enchem as praias brasileiras e oferecerem presentes a Iemanjá. Esta prática, desvinculada do sistema propriamente religioso dos terreiros, mostra a apropriaçáo de símbolos dos rituais afrobrasileiros pela população, que percebe nela símbolos compartilháveis.

A presença da religiosidade afrobrasileira em praias, rios e lagos já se tornaram tão legítima que em muitas existem monumentos a deuses associados a estes espaços. Estes espaços têm se tornado simultaneamente pontos de culto e de turismo. Há alguns anos, a prefeitura da cidade de Salvador (Bahia) revitalizou a área do Dique do Tororó e colocou ali estátuas dos orixás numa homenagem ao local que é utilizado desde o século XIX pelos adeptos do candomblé para louvar as divindades das águas.

Este fato foi duramente criticado pelos evangélicos que questionaram se um estado laico poderia patrocinar símbolos religiosos com dinheiro público. A resposta dada pelo prefeito foi de que os orixás não eram mais apenas símbolos religiosos, mas parte da herança cultural negra de Salvador e da cultura brasileira em ge$\mathrm{ral}^{4}$. Atualmente podemos encontrar no mapa turístico da cidade, ao lado dos endereços de museus e igrejas barrocas, a localização de muitos terreiros. Curioso é que os terreiros são indicados no mapa com o oxê, machado bifacial usado por Xangô, o orixá da justiça.

De que forma então estas esferas (religião, Estado e movimentos políticos) tem se articulado em torno desta disputa pelos símbolos da herança negro-africana no Brasil? Gostaria de comentar algumas destas articulações.

A primeira é aquela ocorrida entre Igreja católica e a população negra e/ou movimento negro. A realização em 1980 do primeiro Seminário de Teologia Negra e o Centenário da Abolição em 1988 impulsionaram o surgimento de diversas associações católicas voltadas ao negro sendo a mais importante a Pastoral Afrobrasileira com o apoio da Conferência $\mathrm{Na}$ - 
cional dos Bispos do Brasil (CNBB). Um grupo de padres negros desde então tem investido num diálogo intenso com a tradição religiosa afrobrasileira 5 .

No diálogo entre catolicismo e candomblé, a pastoral afrobrasileira procura trazer elementos religiosos africanos para o interior da liturgia católica, num processo autodenominado "inculturação da liturgia", cuja apoteose é a "missa afro".

A reinterpretação da imagem de Nossa Senhora da Aparecida, a padroeira negra do Brasil, vista como "Senhora Quilombola” é um bom exemplo. A imagem desta santa é uma estátua de Nossa Senhora da Conceição que teria sido achada num rio com a cabeça separada do corpo, primeiro acharam o corpo e depois a cabeça. As partes foram coladas e um rosário foi colocado em torno do pescoço para disfarçar a emenda, aproximando-a da imagem de Nossa Senhora do Rosário, devoção das populaçóes negras. Temos aqui duas representaçóes: Conceição, padroeira do império português e Rosário, padroeira do povo oprimido, como a população negra. Como se a cabeça da santa fosse o Estado e seu corpo, o Povo. Desde então, e pelo fato de a cor da estátua ter "empretecido”, resultado da ação da água do rio, a imagem tem sido vista por uma parte da população como a padroeira negra do Brasil, conforme se vê nas imagens abaixo ${ }^{6}$.

E mais recentemente sob a influência da pastoral afrobrasileira, Nossa Senhora Aparecida tem sido louvada nas missas como "Mãe Quilombola”.

Assim, a idéia de mãe negra bondosa e pacífica, aos poucos perde espaço para o surgimento de imagens de resistência como a de Anastácia, uma escrava de olhos azuis que teria resistido ao assedio sexual de seu senhor, portanto que se recusou à condição de mãe de uma "mestiçagem forçada”. Sua estátua é apenas uma cabeça de uma mulher amordaçada. Curiosamente, parece indicar o caminho inverso em relação à cabeça colada de Nossa Senhora da Aparecida. Nas missas afros tem sido invocada como santa, uma nova versão de mãe negra. Seu martírio associa-se ao de Jesus, pois ambos portam os instrumentos de tortura: a coroa de espinhos na cabeça ou a mordaça e o colar do cativeiro ${ }^{7}$.

Na liturgia "inculturada" da "missa afro" vemos também que as tradições afros e católicas dialogam. Na comunhão, além do pão e vinho que representam o corpo e sangue de Cristo, os alimentos tradicionalmente oferecidos aos orixás são colocados ao pé do altar, há atabaques e dança dos fieis, e até a presença de sacerdotes das religiōes afrobrasileiras.

No campo das políticas identitárias e reivindicatórias, grandes transformações ocorreram nos anos de 1970 e 1980. As açóes do MNU, Movimento Negro Unificado, foram importantes no sentido de dar continuidade as discussões políticas como o "quilombismo", uma ideologia de resistência em torno da imagem do líder escravo Zumbi dos Palmares. Com a celebração dos 100 anos da Abolição da escravidão, a reivindicação do movimento negro tornou-se cada vez mais articulada. A marcha organizada por este movimento no centro do Rio Janeiro, por exemplo, reivindicou maior participação do Estado brasileiro no combate ao racismo. A mudança da data da celebração da emancipação negra de 13 de maio para o dia 20 de novembro, dia tido como o da morte de Zumbi, foi um ato simbólico e político importante.

Com a redemocratização do país iniciou-se uma nova etapa na relação da sociedade civil com o Estado. A Constituição de 1988 atendeu parcialmente as reivindicaçôes do movimento negro. Foi criada a Fundação Palmares (sob o Ministério da Cultura) e estabeleceu-se o conceito de quilombos como o de áreas habitadas por remanescentes de afrodescendentes com direito à posse da terra. Nos anos de 
1990 o conceito de quilombo estendeu-se para $\mathrm{a}$ área urbana abrangendo inclusive terreiros de candomblé. No governo de Fernando Henrique Cardoso houve o reconhecimento oficial da existência do racismo no Brasil e no governo seguinte, de Luis Inácio Lula da Silva, foi criado um conjunto de açóes direcionado para a população negra como a SEPPIR (Secretaria de Políticas de Promoção da Igualdade Racial), açóes afirmativas e a Lei 10.639 que tornou obrigatório o ensino de História e Cultura Africana e Afrobrasileira nas escolas.

Nesse período, o patrimônio cultural de origem africana começou a ser valorizado nas políticas públicas governamentais incluindo o tombamento de terreiros ${ }^{8}$. Em São Paulo, a demolição de um terreiro localizado numa área em que seria construído um acesso a uma avenida foi interrompida com o pedido da comunidade para o tombamento do terreiro. Menciono estes fatos, ainda que rapidamente, apenas para indicar que a relação entre etnicidade, política identitária e religião começa a se mostrar muito mais complexa com o fortalecimento de agências negras e a pressão da sociedade civil sobre a questão da desigualdade étnica. Entretanto, religião, cor e ação política nem sempre caminham lado a lado.

Darei um exemplo. No Censo de 2000 realizado pelo IBGE vemos que a maioria da população brasileira continua se declarando católica, enquanto apenas $0,3 \%$ se dizem pertencentes às religióes afrobrasileiras. Certamente muitos adeptos destas religióes têm dupla pertença. Em relação à cor, as religióes afrobrasileiras continuam sendo as religióes que reúnem mais adeptos negros e pardos em termos proporcionais (48\%). E entre estas religiôes, o candomblé continua sendo a religião mais negra do Brasil em termos proporcionais. Mas em termos absolutos a maioria da população negra brasileira professa oficialmente a fé católica, o que explica a forca das tradições afrobrasileiras associadas ao catolicismo e as estratégias políticas de sacerdotes negros reivindicando uma identidade cristã e afrobrasileira, enquanto lutam por igualdade racial. Ou seja, ver Nossa Senhora da Aparecida como "Mãe Quilombola” ou reverenciar o poder da escrava Anastácia é potencialmente revelador da força destes símbolos para a população negra e católica brasileira.

Por outro lado, o crescimento das religióes evangélicas, sobretudo as neopentecostais, mostra outro tipo de desafio. O recém criado MNE - Movimento Negro Evangélico, por exemplo, representa uma ação de pastores negros que inspirado no modelo norte-americano de ação política procura negar a necessidade de relacionar identidade negra com as religiōes afrobrasileiras ou as tradiçóes populares do catolicismo. O nome sugestivo do livro de uma liderança desse movimento, pastor Davi (Oliveira, 2004) - A religiáo mais negra do Brasil. Por que mais de oito milhóes de negros são pentecostais?-, indica os caminhos ainda recentes deste movimento. Afinal, em termos absolutos os números realmente indicam que há mais evangélicos negros do que praticantes das religiôes afrobrasileiras e as religióes evangélicas são as que mais crescem no Brasil das últimas décadas. Enfim, se para Edir Macedo (1996), famoso pastor da Igreja Universal do Reino de Deus, é preciso expulsar o "Exu tradição" que faz do Brasil um "vasto terreiro", ele próprio deve o sucesso de sua igreja aos exus que constantemente são expulsos (Silva, 2007).

De qualquer maneira, parece que o Brasil de hoje vive um dilema entre convicçóes religiosas e políticas de apelo étnico. Se uma ala da igreja católica quer abrir as portas para os orixás, alguns terreiros querem se separar dela, consequência em parte do discurso "desvalorizado" sobre o sincretismo e a mestiçagem existente em certos segmentos do candomblé reafricanizado e do movimento negro?. Se os 
evangélicos dizem que nem orixás, santos ou exus fornecem caminhos para o céu ou para a justiça social na terra, ao menos para muitos adeptos estes deuses continuam a atuar em suas vidas como heróis ou vilóes responsáveis por alegrias ou tristezas do dia a dia.

Enfim, se no plano da cultura nacional, os valores afrobrasileiros têm um papel importante no estabelecimento de uma identidade "mestiça” (Brasil como "país das mulatas, do carnaval, samba, futebol, macumba, feijoada e sincretismo"), os grupos que a teriam promovido, por ainda se encontrarem em situação de desvantagem social e econômica, se questionam qual deve ser o melhor caminho a seguir nesta encruzilhada de valores religiosos e açóes políticas.

\section{Esquematizando as conclusóes}

Sem pretender esgotar o tema, mas indicando as diretrizes que parecem permear o debate contemporâneo, podemos dizer que nas religióes afrobrasileiras o papel da etnicidade, quando acionado, vincula-se primordialmente aos símbolos da herança africana, os quais obviamente estão associados à população negra, preferencialmente, e mestiça. Nesse sentido, estas religióes se tornam um campo legítimo de aplicaçáo de políticas públicas do Estado voltadas a estas populações e também um potencial campo de ação para os grupos ou movimentos negros interessados em aglutinar instituiçóes de preservação de patrimônios culturais de origem negro-africana. Nesse caso, verifica-se uma articulação entre símbolos religiosos (vistos como "culturais" ou não), o Estado e os movimentos políticos (negros ou de aliados). Um bom exemplo é a polêmica envolvendo as estátuas dos orixás no Dique do Tororó, em Salvador.

Se pensarmos o "lugar" das religiōes afrobrasileiras no neopentecostalismo, vemos que os símbolos religiosos ou mesmo "culturais" são tidos como resultantes da ação demoníaca. Neste campo, professa-se a necessidade de se romper com a "tradição" do Brasil como um "vasto terreiro", com o "mito do candomblé" (Macedo, 1996). Do ponto de vista das políticas públicas envolvendo a etnicidade, algumas lideranças evangélicas afirmam que há mais negros (em termos absolutos) nas religióes evangélicas do que nas afrobrasileiras. Isso justificaria que as políticas públicas tivessem como parceiras preferencialmente estas igrejas. O "pentecostalismo como opçáo para os pobres, negros e excluídos" (Oliveira, 2004). Nesse sentido, vislumbra-se agora um potencial campo de ação para os grupos ou movimentos negros interessados em difundir discursos e açóes que rompam com certos valores (morais e de conduta pública) presentes nas religióes afrobrasileiras em favor de valores éticos tidos como mais "rígidos".

Por fim, se pensarmos o "lugar" das religióes afrobrasileiras e da etnicidade no catolicismo da pastoral afrobrasileira, vemos que o sincretismo serviu como ponte entre a experiência cristã e as religióes de origem africana levando o catolicismo para o interior dos terreiros. Agora, trata-se de trazer o terreiro para o interior da igreja fazendo com que a missão evangelizadora passe pela troca de "experiências litúrgicas", mas também pela luta pela igualdade e justiça étnico-social.

Ou seja, as formas pelas quais essas teologias e práticas se relacionam com esses novos agentes sociais e políticos parecem induzir a posicionamentos inusitados sobre o que é sincretismo, mestiçagem, herança africana, cultura brasileira, participação política, justiça social etc. Um campo de observação bastante interessante que merece pesquisas que associem religiâo, cultura e esfera pública sob a perspectiva destes atores que expressam na forma de transes - de orixás, espírito santo e exus - concepções sobre o que é ou deveria ser o Brasil. 


\section{Anexo - Religióes Afrobrasileiras e Espaço Público - Uma Cronologia}

\begin{tabular}{|c|c|}
\hline $\begin{array}{l}1591-95 \\
1618-21 \\
1763-69\end{array}$ & $\begin{array}{l}\text { Visitações do Tribunal do Santo da Inquisição: praticantes } \\
\text { de religiosidades origem africana e afrobrasileira são } \\
\text { perseguidos }\end{array}$ \\
\hline 1824 & $\begin{array}{l}\text { Constituição do Império: Catolicismo é religião oficial. } \\
\text { Proibição de templos não católicos (Outras religiões } \\
\text { devem ficar restritas ao espaço doméstico ou em edifícios } \\
\text { sem aparência externa de templo). Notícias em jornais } \\
\text { de terreiros instalados em espaço urbanos. }\end{array}$ \\
\hline séc. XIX & $\begin{array}{l}\text { Fundação dos terreiros mais antigos ainda em funciona- } \\
\text { mento: Casa das Minas e Casa de Nagô (São Luís), Sítio } \\
\text { do Pai Adão (Recife), Casa Branca do Engenho Velho } \\
\text { (Salvador). }\end{array}$ \\
\hline 1890 & $\begin{array}{l}\text { Código Penal Republicano. Institui o crime de espiritismo, } \\
\text { magia e seus sortilégios, (art. 157) e o de curandeirismo } \\
\text { (art. 158), pelos quais muitos praticantes das religiões } \\
\text { afrobrasileiras são acusados e julgados. }\end{array}$ \\
\hline 1891 & $\begin{array}{l}\text { Constituição Republicana. Institui a separação entre } \\
\text { Estado e religião e a liberdade de culto. Melhoram as } \\
\text { condições de organização dos terreiros }\end{array}$ \\
\hline c.1890 & $\begin{array}{l}\text { Casa de Tia Ciata (Hilária Batista de Almeida) e de outras } \\
\text { "tias baianas", nas proximidades da Praça Onze, tornam- } \\
\text { se núcleos de difusão do samba carioca com a presença } \\
\text { de Donga, Sinhô, João da Baiana, entre outros. }\end{array}$ \\
\hline 1900 & $\begin{array}{l}\text { Publicação de } 0 \text { animismo fetichista dos negros bahianos, } \\
\text { de Raimundo Nina Rodrigues. A primeira etnografia } \\
\text { sobre as religiões afrobrasileiras }\end{array}$ \\
\hline 1908 & $\begin{array}{l}\text { Zélio de Moraes funda a Tenda Espírita Nossa Senhora } \\
\text { da Piedade, tida, segundo um dos mitos de origem da } \\
\text { umbanda, como a pioneira desta religião }\end{array}$ \\
\hline 1910 & $\begin{array}{l}\text { Fundação do Terreiro do Axé Opô Afonjá, por Mãe Aninha } \\
\text { (Eugênia Anna dos Santos) em Salvador. }\end{array}$ \\
\hline 1912 & $\begin{array}{l}\text { "Operação Xangô": invasão e destruição dos principais } \\
\text { terreiros de Maceió e vizinhanças, acusados de serem } \\
\text { aliados do governador deposto Euclides Malta. }\end{array}$ \\
\hline $1930-45$ & $\begin{array}{l}\text { Governo ditatorial de Getúlio Vargas. Funcionamento } \\
\text { dos terreiros sob severa vigilância das Secretárias da } \\
\text { Segurança Pública e dos Serviços de Higiene Mental }\end{array}$ \\
\hline \multirow{3}{*}{1934} & $\begin{array}{l}\text { Publicação de } 0 \text { Negro Brasileiro, de Arthur Ramos, } \\
\text { primeiro volume da coleção Bibliotheca de Divulgação } \\
\text { Scientííca, principal divulgadora de obras sobre as } \\
\text { religiões afrobrasileiras. }\end{array}$ \\
\hline & $\begin{array}{l}\text { Publicação de Jubiabá, de Jorge Amado. Os temas do } \\
\text { candomblé passam a ser uma marca do mais lido escritor } \\
\text { brasileiro da época. }\end{array}$ \\
\hline & $\begin{array}{l}\text { Realização do I Congresso Afrobrasileiro (Recife), orga- } \\
\text { nizado por Gilberto Freire. }\end{array}$ \\
\hline
\end{tabular}

\begin{tabular}{|c|c|}
\hline 1937 & $\begin{array}{l}\text { Realização do II Congresso Afrobrasileiro (Salvador), or- } \\
\text { ganizado por Édison Carneiro e Aydano do Couto Ferraz. }\end{array}$ \\
\hline 1938 & $\begin{array}{l}\text { Missão de Pesquisas Folclóricas, idealizada por Mário de } \\
\text { Andrade, registra cenas e músicas de rituais religiosos } \\
\text { afrobrasileiros e festas populares no Norte e Nordeste. }\end{array}$ \\
\hline \multirow[b]{2}{*}{1939} & $\begin{array}{l}\text { Criação, no Rio de Janeiro, da União Espírita de Umbanda } \\
\text { do Brasil, a primeira federação desta religião no país. }\end{array}$ \\
\hline & $\begin{array}{l}\text { Carmen Miranda canta "0 que é que a baiana tem?", no } \\
\text { filme "Banana da Terra", vestida de baiana, uma estiliza- } \\
\text { ção do traje típico das mães-de-santo do candomblé. }\end{array}$ \\
\hline 1940 & $\begin{array}{l}\text { Código Penal mantém os delitos de charlatanismo (art. } \\
\text { 283) e curandeirismo (art. 284), pelos quais praticantes } \\
\text { das religiões afrobrasileiras continuam sendo acusados. }\end{array}$ \\
\hline 1941 & $\begin{array}{l}\text { Realização do } 1^{\circ} \text { Congresso Brasileiro de Espiritismo de } \\
\text { Umbanda }\end{array}$ \\
\hline 1946 & $\begin{array}{l}0 \text { francês Pierre Verger desembarca em Salvador onde } \\
\text { passa a residir tornando-se um dos principais fotógrafos } \\
\text { e etnógrafos do candomblé e de suas origens africanas }\end{array}$ \\
\hline \multirow{2}{*}{1961} & Realização do $2^{\circ}$ Congresso de Umbanda \\
\hline & $\begin{array}{l}\text { Publicação de } 0 \text { candomblé da Bahia - rito nagô, de } \\
\text { Roger Bastide. }\end{array}$ \\
\hline \multirow{2}{*}{1964} & $\begin{array}{l}\text { Festas das religiões afrobrasileiras (como a Festa de } \\
\text { lemanjá) passam a fazer parte dos calendários turísticos } \\
\text { regionais }\end{array}$ \\
\hline & $\begin{array}{l}\text { Dia } 31 \text { de dezembro é declarado oficialmente Dia do } \\
\text { Umbandista }\end{array}$ \\
\hline \multirow{2}{*}{1971} & $\begin{array}{l}\text { Morre Joãozinho da Goméia, um dos mais populares } \\
\text { pais-de-santo do Rio de Janeiro e São Paulo. }\end{array}$ \\
\hline & $\begin{array}{l}\text { Publicação de As religiões africanas no Brasil, de Roger } \\
\text { Bastide. }\end{array}$ \\
\hline 1976 & $\begin{array}{l}\text { Inauguração da estátua de lemanjá na Praia Grande, } \\
\text { São Paulo, e inclusão de sua festa, realizada em } 8 \text { de } \\
\text { dezembro, no calendário turístico oficial da cidade. }\end{array}$ \\
\hline 1982 & $\begin{array}{l}\text { Fundação do Museu Afrobrasileiro em Salvador com } \\
\text { acervo de fotos e documentos etnográficos de Pierre } \\
\text { Verger e painéis dos orixás esculpidos na madeira por } \\
\text { Carybé }\end{array}$ \\
\hline 1983 & $\begin{array}{l}\text { Morre Clara Nunes, a cantora que mais vendeu discos } \\
\text { com temas das religiões afrobrasileiras. }\end{array}$ \\
\hline 1984 & $\begin{array}{l}\text { Criação do Conselho Estadual de Participação e Desen- } \\
\text { volvimento da Comunidade Negra em São Paulo com a } \\
\text { participação de membros das religiões afrobrasileiras. }\end{array}$ \\
\hline 1986 & $\begin{array}{l}\text { Morre Menininha do Gantois, a mais popular mãe-de- } \\
\text { santo do Brasil. }\end{array}$ \\
\hline
\end{tabular}




\begin{tabular}{|c|c|}
\hline $1986-2005$ & $\begin{array}{l}\text { Processo de tombamento de terreiros por órgãos } \\
\text { governamentais: } \\
\text { (1986) Casa Branca do Engenho Velho (Salvador, IPHAN). } \\
\text { (1990) Axé llê Obá (São Paulo, CONDEPHAT). } \\
\text { (1999) Ilê Axé Opô Afonjá (Salvador, IPHAN). } \\
\text { (2002) Ilê Axé Omim lyá Yamassê - Gantois (Salvador, } \\
\text { IPHAN). } \\
\text { (2002) Casa das Minas (São Luís, Maranhão, IPHAN). } \\
\text { (2003) Inzo Manzo Bandukenké Bate Folha (Salvador, } \\
\text { IPHAN). } \\
\text { (2005) Ilê Mariolaje - Olga do Alaketu (Salvador, IPHAN). }\end{array}$ \\
\hline 1988 & $\begin{array}{l}\text { Marcha de Zumbi contra a discriminação (Marcha do } \\
\text { Centenário da Abolição, RJ) } \\
\text { Criação da Fundação Palmares (vinculada ao Ministério } \\
\text { da Cultura). }\end{array}$ \\
\hline 1995 & $\begin{array}{l}\text { Marcha Zumbi dos Palmares, contra o racismo, pela } \\
\text { cidadania e pela vida, (Brasília, MNU), celebrando os } \\
300 \text { anos da morte de Zumbi dos Palmares. Documento } \\
\text { produzido cobra políticas de proteção às religiões } \\
\text { afrobrasileiras por parte do Estado. }\end{array}$ \\
\hline \multirow[t]{2}{*}{2000} & $\begin{array}{l}0 \text { Censo do IBGE (2000) aponta que apenas 0,3 \% da } \\
\text { população brasileira se auto-declara pertencente às } \\
\text { religióes afrobrasileiras e que estas possuem o maior } \\
\text { número de adeptos negros e pardos em termos propor- } \\
\text { cionais (48\%). }\end{array}$ \\
\hline & $\begin{array}{l}\text { Promulgação do Estatuto da Igualdade Racial (Projeto } \\
\text { de Lei 3.198) }\end{array}$ \\
\hline \multirow[t]{2}{*}{2003} & $\begin{array}{l}\text { Lei } 10.639 \text { do Governo Federal torna obrigatório o ensino } \\
\text { da História da África e Cultura Afrobrasileira nas escolas } \\
\text { do país. }\end{array}$ \\
\hline & $\begin{array}{l}\text { Criação da SEPPIR (Secretaria Especial de Políticas de } \\
\text { Promoção da Igualdade Racial) }\end{array}$ \\
\hline 2004 & $\begin{array}{l}\text { Salvador institui o Dia Municipal de Combate à Intolerân- } \\
\text { cia Religiosa ( } 21 \text { de janeiro) em homenagem à morte de } \\
\text { mãe Gilda, vítima de perseguição religiosa. }\end{array}$ \\
\hline 2005 & $\begin{array}{l}\text { Fundação do Museu Afro Brasil em São Paulo, reunindo } \\
\text { o maior acervo nacional de obras e documentos sobre a } \\
\text { cultura afrobrasileira. }\end{array}$ \\
\hline 2009 & $\begin{array}{l}\text { Candomblé e Umbanda são declarados patrimônios } \\
\text { imateriais do Estado do Rio de Janeiro }\end{array}$ \\
\hline
\end{tabular}

\section{Notas}

1. A pesquisa foi concebida por Vagner Gonçalves da Silva e Rita Amaral e sua realização contou com o auxílio financeiro da FAPESP e atualmente do CNPq. Para uma visão geral de sua proposta, veja Amaral e Silva, 2006 e o site: http://www.doafroaobrasileiro.org/.).
2. Estes temas foram abordados em seminários e palestras realizados em universidades norte-americanas durante o período de meu pós-doutoramento (20082009)

3. A literatura sobre a "guerra santa" neopentecostal é bastante extensa. Uma visão contemporânea deste aspecto que envolve aspectos de intolerância religiosa pode ser encontrada em Silva, 2007.

4. Sobre este tema, veja Sansi, 2007.

5. Sobre este diálogo, consulte, entre outros, Oliveira, 2011.

6. Sobre este processo de "empretecimento" da imagem da santa, veja Santos, 2007.

7. Sobre a Escrava Anastácia, veja, entre outros, Dias, 2007.

8. Veja Anexo - Religióes Afrobrasileiras e Espaço Público - Uma Cronologia.

9. Sobre o tema, veja Collins, 2004; Santos, 2005; Van de Port, 2005; Hafbauer, 2006; Montero, 1994, entre outros.

\section{Referências bibliográficas}

AMARAL, Rita \& SILVA, Vagner Gonçalves da. "Foi conta para todo canto: As religiōes afrobrasileiras nas letras do repertório musical popular brasileiro". Afro-Ásia, Salvador, UFBA, n. 34, pp. 189-235. 2006. Disponível em: http://www.afroasia.ufba.br/pdf/afroasia34_pp189_235_Amaral_Vagner.pdf.

"Religióes afrobrasileiras e cultura nacional: uma etnografia em hipermídia”. Caderno Pós Ciências Sociais. V.3, n.6, jul/dez, São Luis, MA, pp. 107-130, 2006. http://www.pgcs.ufma.br/n6/n6_Rita_Amaral. pdf.

"Fatumbi: o Destino de Verger". In: VERGER, Pierre. Saída de Iaô. São Paulo, Axis Mundi e Fundação Pierre Verger, 2002, pp. 29-48.

BAPTISTA, Rachel Rua. Tem orixá no samba: Clara Nunes e a presença do candomblé e da umbanda na música popular brasileira. Dissertação de mestrado. São Paulo, USP, 2005.

BORGES, Rosangela. Axé, Madona Achiropita!: presença da cultura afrobrasileira nas celebraçóes da Igreja Nossa Senhora Achiropita em São Paulo. São Paulo: Pulsar, 2001.

BOURDIEU, Pierre. A economia das trocas simbólicas. São Paulo: Perspectiva, 1987.

BRUMANA, Fernando \& MARTINEZ, Elda. Marginália sagrada. Campinas: Unicamp, 1991. 
BURDICK, John. "The Catholic afro mass and the dance of eurocentrism in Brazil". In: GOLDSMIDT, Henry \& McALISTER, Elizabeth (eds). Race, Nation, and Religion in the Americas. New York: Oxford University Press, 2004.

BURDICK, John. "What is the Color of the Holy Spirit? Pentecostalism and Black Identity in Brazil". Latin American Research Review, vol. 34, n. 2, 1999.

CAMARGO, Cândido Procópio de. Kardecismo e Umbanda. São Paulo: Pioneira, 1961.

COLLINS, John. "'X Marks the Future of Brazil': Racial Politics, Bedeviling Mixtures and Protestant Ethics in a Brazilian Cultural Heritage Center”. In: SHRYOCK, Andrew (ed). Off Stage/On Display: Intimacies and Ethnographies in the Age of Public Culture. Stanford University Press, 2004.

DAMASCENO, Caetana. Cantando pra subir: orixá no altar, santo no peji. Dissertaçáo de Mestrado do Programa de Pós-Graduação em Antropologia Social Museu Nacional UFRJ, 1990.

DaMATTA, Roberto. Carnavais, malandros e heróis: para uma sociologia do dilema brasileiro. Rio de Janeiro: Rocco, 1997. 6 ed.

FRY, Peter. Para Inglês Ver. "Feijoada e Soul Food: 25 anos depois". In: ESTERCI, Neide, FRY, Peter e Mirian GOLDENBERG (orgs.). Fazendo antropologia no Brasil. Rio de Janeiro: DP\&A, 2001.

GILROY, Paul. The Black Atlantic: Modernity and Double Consciousness. Cambridge: Harvard UP, 1992.

GREENFIELD, Sidney. "The reinterpretation of Africa: Convergence and syncretism in Brazilian Candomblé". In: GREENFIELD \& DROOGERS (eds). Reinventing religion. Syncretism and transformation in Africa and the Americas. Rowman \& Littlefield Publishers, 2001.

HOFBAUER, Andreas. Uma história de branqueamento ou o negro em questão. São Paulo: UNESP, 2006.

MACEDO, Edir. Orixás, Caboclos e Guias: Deuses ou Demônios? Rio de Janeiro: Editora Universal, 1996.

MAGGIE, Yvonne. Medo de Feitiço: Relações entre magia e poder no Brasil. Rio de Janeiro: Arquivo Nacional, 1992 (Introdução e Conclusão).

MATORY, James Lorand - Black Atlantic Religion: Tradition, Transnationalism, and Matriarchy in the Afrobrazilian Candomble. Princeton University Press, 2005.

MONTERO, Paula. "Magia, racionalidade e sujeitos políticos”. Revista Brasileira de Ciências Sociais, n. 26, 1994.

MONTES, Maria Lucia. "Figuras do Sagrado: Entre o público e o privado". In: História da vida privada no
Brasil. Vol. 4, São Paulo, Companhia das Letras, 1998. OLIVEIRA, Marco Davi. A religiāo mais negra do Brasil. São Paulo: Mundo Cristão, 2004.

OLIVEIRA, Rosenilton Silva de. Paixão como festa: significados das liturgias "inculturadas" afrobrasileiras. São Paulo: Universidade de São Paulo. Dissertação de mestrado, 2011.

ORTIZ, Renato. A Morte Branca do Feiticeiro Negro. Petrópolis: Vozes. 1978.

PEREIRA, João Baptista Borges. "A cultura negra: resistência de cultura à cultura de resistência”. Dédalo, n.23, São Paulo, 1984.

SANCHIS, Pierre (org). Fiéis \& cidadãos: percursos de sincretismo no Brasil. Rio de Janeiro: Ed. UERJ, 2001.

"Inculturação? Da cultura à identidade, um itinerário político no campo religioso: o caso dos agentes de pastoral negros". In: CAROSO, Carlos; BACELAR, Jeferson (org.). Faces da tradição afrobrasileira: religiosidade, sincretismo, antisincretismo, reafricanização, práticas terapêuticas, etnobotãnica e comida. Rio de Janeiro/Salvador: Pallas/CNPq, 2002.

SANSI, Roger. Fetishes \& Monuments - Afrobrazilian Art and Culture in the 20 $0^{\text {th }}$ Century. New York: Berghahn Books, 2007.

SANTOS, Jocélio Teles. O poder da cultura e a cultura no poder. A disputa simbólica da herança cultural negra no Brasil. Salvador: Edfuba, 2005.

SANTOS, Lourival dos. "A cor da santa: Nossa Senhora Aparecida e a construção do imaginário sobre a padroeira do Brasil”. In: SILVA, Vagner Gonçalves da. Imaginário, Cotidiano e Poder. São Paulo: Summus/Selo Negro, 2007. Coleção Memória Afrobrasileira. Vol 3.

SELKA, Stephen. Religion and the politics of ethnic identity in Bahia, Brazil. The University Press of Florida, 2007.

SERRA, Ordep. Águas do Rei. Petrópolis: Vozes, 1995.

SILVA, Vagner G. da. "Religiōes afrobrasileiras. Construção e legitimação de um campo do saber acadêmico" (1900-1960). Revista USP, São Paulo, USP-CCS, n. 55 (pp. 82-111), 2002.

. "Entre a Gira de Fé e Jesus de Nazaré: Relações sócio-estruturais entre neopentecostalismo e religióes afrobrasileiras". In: (org.). Intolerância religiosa. Impactos do neopentecostalismo no campo religioso afrobrasileiro. São Paulo, EDUSP, 2007.

. "Sagrados e Profanos: religiosidades afrobrasileiras e seus desdobramentos na cultura nacional". In: $C a$ tálogo do Museu Afro Brasil. Secretaria de Cultura da Prefeitura da Cidade de São Paulo / IFF / SEPPIR. 2006, pp. 149-157. 
Candomblé e Umbanda: Caminhos da Devoção Brasileira. São Paulo: Selo Negro, 2005.

. Orixás da Metrópole. Petrópolis: Vozes, 1995.

SOUZA, Mônica Dias de. "Escrava Anastácia e pretos-velhos: a rebelião silenciosa da memória popular”. In: SILVA, Vagner Gonçalves da. Imaginário, Cotidiano e Poder. São Paulo. Summus/Selo Negro, 2007. Coleção Memória Afrobrasileira. Vol. 3.
VAN DE PORT, Mattijs. “Candomblé in pink, green and black. Re-scripting the Afrobrazilian religious heritage in the public sphere of Salvador, Bahia”. Social Anthropology, 2005, 13, p. 13-26.

YEVINGTON, Kevin. Afro-Atlantic Dialogues. Anthropology in the Diaspora. Santa Fe: SAR Press, 2006.

\section{autor Vagner Gonçalves da Silva}

Professor do Departamento de Antropologia Social / USP

Pós-Doutor em Antropologia Social / Harvard University

Recebido em 10/10/2011

Aceito para publicação em 10/10/2011 